\title{
Relationships between vitamin $A$, iron status and helminthiasis in Bangladeshi school children
}

\author{
$V_{\text {Persson }}{ }^{1, *}$, F Ahmed ${ }^{2}$, M Gebre-Medhin $^{1}$ and T Greiner ${ }^{1}$ \\ ${ }^{1}$ Section for International Maternal and Child Health (IMCH), Uppsala University, 75185 Uppsala, Sweden: \\ ${ }^{2}$ Institute of Nutrition and Food Science, Dhaka University, Dhaka 100, Bangladesh
}

Submitted 9 April 1999: Accepted 1 September 1999

\begin{abstract}
Objective: To explore the relationships between biochemical indicators of vitamin A and iron status and the intestinal helminths Ascaris lumbricoides and hookworm in primary school children.

Setting: Two rural governmental schools in northwestern Bangladesh.

Design: Cross-sectional study.

Subjects: The sample consisted of 164 children in grades 3-5.

Methods: Serum retinol and $\beta$-carotene (by high-performance liquid chromatography, HPLC), haemoglobin (HemoCue), ferritin (enzyme-linked immunoadsorbent assay, ELIZA) and height and weight were measured. Dietary intake of vitamin A was assessed using a food frequency questionnaire and faecal analyses were done using Stoll's egg-count technique.

Results: The mean serum retinol was $26.8 \mu \mathrm{g} \mathrm{dl}^{-1}$ and $20 \%$ had a level of $<20 \mu \mathrm{g} \mathrm{dl}^{-1}$, the cut-off value for low vitamin A status. There was a strong positive association between serum $\beta$-carotene and serum retinol $(r=0.44, P<0.001)$, suggesting those with higher retinol levels had a higher carotene intake. Thirty-one per cent were anaemic $\left(\mathrm{Hb}<11.5 \mathrm{~g} \mathrm{dl}^{-1}\right.$ ), 30\% had iron deficiency (serum ferritin $<12.0 \mu \mathrm{g} \mathrm{l}^{-1}$ ) and $14 \%$ were suffering from iron deficiency anaemia. Children with a serum retinol level of $20 \mu \mathrm{g} \mathrm{dl}^{-1}$ had significantly lower ferritin (14.0 compared to $26.0 \mu \mathrm{g} \mathrm{l}^{-1}, P=0.005$ ) and $\mathrm{Hb}$ levels (11.7 compared to $12.4 \mathrm{~g} \mathrm{dl}^{-1}, P=0.005$ ) than those with higher levels. The proportion of iron deficiency anaemia was significantly greater among children with hookworm. Our data suggest that hookworm exerts its impact on iron status independently of the vitamin A status of the host.

Conclusions: Programmes to improve iron status should consider including both vitamin A prevention programmes and deworming.
\end{abstract}

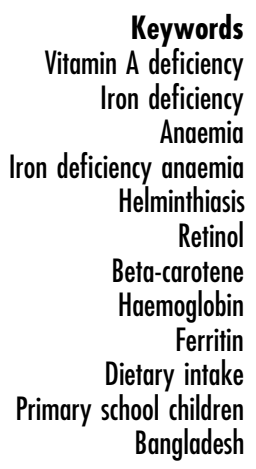

Iron deficiency anaemia is the most common nutritional deficiency in the world and impairs immunity and reduces physical and mental capacities of populations ${ }^{1}$. Published reports regarding iron deficiency in Bangladesh are rare, but it is estimated that about $70 \%$ of women suffer from anaemia $^{2}$. Iron supplementation programmes are generally only targeted at pregnant women. However, in the 1981-82 National Nutrition Survey of Bangladesh as many as $74 \%$ of children aged 5-14 years were found to be anaemic $^{2}$. No parameters were measured to determine how much of this was linked to iron deficiency. However, in a study on female adolescents in Dhaka, serum total iron binding capacity was negatively correlated with haemoglobin (Hb), suggesting that an important proportion of the anaemia could be explained by iron deficiency $^{3}$.

There is clear evidence of an association between serum levels of vitamin A and iron indicators ${ }^{3-5}$ and it may be that vitamin A exerts an influence on the metabolic availability of iron ${ }^{6}$. Therefore, the possibility that iron deficiency anaemia partly could be a consequence of poor vitamin A status would have widespread implications for public health interventions currently adopted for its prevention. Vitamin A deficiency (VAD) was previously identified as a public health problem in Bangladesh ${ }^{7}$ but several interventions have been implemented to alleviate it, and the national vitamin A survey in 1997 found that only $0.67 \%$ of children aged 6-59 months suffered from night blindness $(\mathrm{XN})^{8}$, below the $1 \%$ cut-off point for a public health problem in that age group.

However, very little is known about the vitamin A status of primary school children in Bangladesh. A study in Matlab found that $0.13 \%$ of the girls and $0.45 \%$ of the boys aged 7-20 years suffered from $\mathrm{XN}^{9}$. A study of 242 school children in urban Dhaka ${ }^{10}$, aged 5-12 years found that about $20 \%$ of the children had serum retinol levels of less than $30 \mu \mathrm{g} \mathrm{dl}^{-1}$. However, only a limited number of studies with small sample sizes have been published on vitamin A status as measured by serum retinol in school-aged children living in rural areas of Bangladesh. A study in 
Rangpur District* found that the mean serum retinol levels of children aged 7-8 and 9-15 years were $17.6 \mu \mathrm{g} \mathrm{dl}^{-1}$ and $25.2 \mu \mathrm{g} \mathrm{dl}^{-1}$ in children with $\mathrm{XN}$ and $22.4 \mu \mathrm{g} \mathrm{dl}^{-1}$ and $29.2 \mu \mathrm{g} \mathrm{dl}^{-1}$ in children without XN, respectively $(n=92)^{11}$.

Intestinal helminths such as Ascaris lumbricoides (ascaris) and Necator americanus and Ancylostoma duodenale (hookworm) are prevalent in Bangladesh in all age groups ${ }^{12,13}$. Ascaris has been associated with $\mathrm{VAD}^{14,15}$, and hookworm causes blood loss, leading to iron deficiency anaemia ${ }^{16,17}$. Studies have shown that worm load and faecal egg count are strongly associated with amount of blood loss ${ }^{18,19}$ and $\mathrm{Hb}$ levels ${ }^{17,20,21}$. However, the worm burden above which this becomes apparent seems to depend on the iron stores of the population $^{22}$.

Against this background, the aim of the present study was to describe the extent of VAD, iron deficiency and anaemia in primary school children in rural Bangladesh. We also explored the relationship between biochemical indicators of vitamin A, iron status and the intestinal helminths Ascaris and hookworm. We hypothesized that hookworm infection has a greater impact on iron status in those with lower vitamin A status.

\section{Materials and methods}

This study was conducted from March to May 1998 in connection with a dietary intervention aimed at investigating whether it was possible to improve vitamin A status through supplemental feeding with dark green leafy vegetables in school children after deworming.

\section{Study population}

The study sample consisted of primary school children from grades 3-5 at one rural school in Panchargar District, and another in Thakurgaon District. Both schools are governmental and were selected because they were within an hour's distance of the field laboratory in Thakurgaon town, were known by our collaborating partner, the Worldview International Foundation, and yet had not received any nutrition intervention within the last 3 years. The purpose of the study was explained to the administrators at each school. After having obtained permission from the school, the parents were invited to the school and the purpose of the study was explained to them. Only those children who obtained verbal parental consent (due to low literacy rate) were included. Prior to the intervention, all children in grades 3-5 from the two schools were screened for intestinal helminths. Out of 302 children screened, $47 \%$ (143) were found to be positive, either for Ascaris (32\%), hookworm (5\%) or both (10\%). To complete the desired sample size, these 143 , plus 25

*Bangladesh is divided into six divisions. Each division consists of several districts and each district is divided into thanas (subdistricts). Rangpur, Thakurgaon and Panchargar Districts belong to Rajshahi Division. children with an unhygienic toilet (kacha) were selected. After four of the children dropped out, the final sample was 164 children. All had access to tube-well water, 78\% were using an unhygienic toilet (kacha) and the rest a constructed one (pucca), and 93\% were living in houses with an earthen floor. The mean reported age of the children was 9.3 years (median 9.5; range 6-12 years) and $53 \%$ were girls. The study was approved by the Bangladesh Medical Research Council and the Uppsala University Committee on Research Ethics.

\section{Antbropometry}

Weight was measured to the nearest $200 \mathrm{~g}$ on a digital scale (Soehnle, Germany). The children were measured barefoot and with only light clothing. Height was measured using a stadiometer (Somatomètre, Inter 16, CMS equipment Ltd, UK) marked at $0.1 \mathrm{~cm}$ intervals. Since many children were unsure of their ages, it was decided to only calculate weight for height $(\mathrm{W} / \mathrm{H})$, using United States National Center for Health Statististics' (NCHS) reference data (1976). As recommended by WHO, the data are related to the NCHS by standard deviation scores ${ }^{23}$.

\section{Dietary interviews}

A questionnaire was developed to obtain information on frequency of intake of dietary sources of vitamin A and on meat intake. Furthermore, the children were asked about the presence or absence within the past week of various symptoms thought to be related to vitamin A status, such as fever, $\mathrm{XN}$, diarrhoea and acute respiratory infection, as well as standard of housing (type of roof, wall, floor and toilet).

\section{Blood sampling}

A sample of $5 \mathrm{ml}$ of venous blood was taken from the cubital vein from each participant. The blood was placed in a glass centrifuge tube and immediately wrapped in foil to protect against degradation of vitamin A by light. Within 2 hours the blood was transported to the field laboratory and centrifuged at $1000 \mathrm{~g}$ for $10 \mathrm{~min}$. Serum was then separated and kept frozen at $-10^{\circ} \mathrm{C}$ for 3 days, and then transported to Dhaka on dry ice and kept frozen at $-20^{\circ} \mathrm{C}$ until $\beta$-carotene, retinol and ferritin analyses were done 3-6 months later.

\section{Analytical procedures}

Serum retinol and $\beta$-carotene levels were determined by the HPLC procedure. Retinol was extracted by using hexane after deproteinization with ethanol containing retinyl acetate (Sigma, St Louis, USA) as the internal standard for retinol and evaporated to dryness under nitrogen gas. The residue was redissolved in $100 \mu \mathrm{l}$ ethanol. A portion $(20 \mu \mathrm{l})$ of the sample was injected into the HPLC system. Retinol was separated on a reverse phase $\mathrm{C}_{18}$ column with a methanol-water $(96: 4, \mathrm{v} / \mathrm{v})$ solvent system and monitored spectrophotometrically at 
$\mathrm{A}_{325}$ (solvent delivery system, Waters 510; absorbance detector, Waters 486; data module, Waters 7460). The interassay and intra-assay variation for serum retinol was $2.7 \%$ and $2.6 \%$, respectively.

Beta-carotene was extracted by using $100 \mu \mathrm{l}$ sodium dodecyl sulphate (SDS; $10 \mathrm{~mm}$ in water). $\beta$-apo- $8^{\prime}$ carotenal (Sigma, St Louis, USA) in ethanol was added as the internal standard. The mixture was extracted twice by using hexane and evaporated to dryness under nitrogen. The residue from the two extractions was redissolved in $25 \mu \mathrm{l}$ of the tetrahydrofuran (THF) followed by $75 \mu \mathrm{l}$ of the mobile phase. A portion $(20 \mu \mathrm{l})$ of the sample was injected into the HPLC system. $\beta$-carotene was separated on a reverse phase $\mathrm{C}_{18}$ column with a solvent system containing $80 \%$ acetonitrile, 10\% THF, 9\% methanol with $200 \mathrm{~mm}$ ammonium acetate, $1 \%$ water and $0.1 \%$ triethyl amine, and monitored spectrophotometrically at $\mathrm{A}_{450}$ (solvent delivery system, Waters 510; absorbance detector, Waters 486; data module, Waters 7460). The interassay and intra-assay variation for serum $\beta$-carotene were $5.7 \%$ and $4.0 \%$, respectively.

C-reactive protein (CRP) and serum ferritin were analysed by routine methods at the Department of Clinical Chemistry, Uppsala University Hospital. CRP was analysed by a turbometric method using a polymer on a Hitachi 911. The measuring interval is $0-175 \mu \mathrm{gl}^{-1}$ with a reference interval of $<10 \mu \mathrm{gl}^{-1}$. The coefficient of variation (CV) was $10 \%$ at $20 \mu \mathrm{gl}^{-1}$. Levels below $10 \mu \mathrm{gl}^{-1}$ are given as $<10 \mu \mathrm{gl}^{-1}$ and levels $>10 \mu \mathrm{gl}^{-1}$ were taken as an indicator of acute infection, and these children were excluded $(n=5)$. Serum ferritin was analysed using a double monoclonal antibody technique. The CV was $4.2 \%$ at $135 \mu \mathrm{gl}^{-1}$ and $7.8 \%$ at $14.9 \mu \mathrm{g} \mathrm{l}^{-1}$. Hb content was determined on the spot using the HemoCue method (HemoCue Inc, Sweden) on venous blood.

\section{Faecal analyses}

Stool samples were examined to determine the worm burden of the study participants by using Stoll's dilution egg-count technique (Suzuki, 1981) ${ }^{24}$. A $2 \mathrm{ml}$ sample of faeces was added to $58 \mathrm{ml}$ of $0.1 \mathrm{~N} \mathrm{NaOH}$ and the flask was shaken (mixed) vigorously. An aliquot of $0.15 \mathrm{ml}$ was then put onto a clean slide upon which a cover slip was placed. The total number of eggs were counted microscopically and expressed as the number of eggs per gram of stool by multiplying by a factor of 200. Further correction factors were used for the nature of the faeces.

\section{Statistical analyses}

Data were analysed with the SPSS/PC statistical package (8.0). The distribution of each variable was tested for normality before analyses, using the KolmogorovSmirnov goodness of fit test. Where necessary, data were normalized using appropriate transformations. Data are presented as means \pm standard deviations when normally distributed and medians and $25-75$ percentile when not normally distributed. Proportions below the cut-off points determined by WHO are also presented. Pearson's correlation test was used to examine the association between serum retinol and $\beta$-carotene. Chi-square tests, independent sample $t$-tests and analyses of variance (ANOVA) were used to assess the effect of certain differences between groups, and if statistical differences were found, post hoc tests were performed (Bonferroni). Multiple regression analysis was used to study the relationship between iron status and the explanatory variables retinol and hookworm, and to control for interactions.

\section{Results}

\section{Antbropometry}

Seventeen per cent of the children were taller than the maximum reference value used for $\mathrm{W} / \mathrm{H}^{25}$ and thus the results are based on data for only $83 \%$ of the sample. The proportion of that subsample below $-2 \mathrm{SD}$ in $\mathrm{W} / \mathrm{H}$ was $21 \%$. Height and weight data are presented in Table 1. Mean $\mathrm{W} / \mathrm{H}$ was $-1.27 \mathrm{SD}$ and there was no statistically significant difference between boys and girls.

\section{Dietary data}

The median frequency of consumption of plant sources of vitamin A during the 7 days preceding the interview was 2.0 (25-75 percentile: $1-4)$. Dark green leafy vegetables were most commonly consumed, with a median consumption of 2.0 (1-4) times per week. The median total frequency of consumption of animal sources of vitamin A was 4.0 (2-8) within the last week (mean: 5.1). However, the median consumption of eggs, liver and small fish were each zero (means: 0.9, 0.2 and 1.4, respectively) and milk was 2.0 (1-4) times in the last 7 days. The weighted total consumption of vitamin A-rich sources, using the conventional conversion factor of 6 for plant sources ${ }^{26}$ was $4.3 \pm 5.1$. The median consumption of meat (beef, mutton or chicken) was $1.0(0-2)$ times per week. Proportions of children consuming more or less than certain cut-off values are presented in Table 2 .

\section{Intestinal belmintbs}

Data on intestinal helminth infestations are presented in Table 1. Eighty-two per cent of the children had intestinal helminths (keeping in mind this was a purposeful subsample of those reported on earlier who were screened for helminths). Of these 55\% had ascaris, 9\% had hookworm and $18 \%$ both. Of those with ascaris, 70\%, 29\% and 1\%, respectively were lightly (1-4999 eggs g $^{-1}$ ), moderately (5000-49999 eggs $\mathrm{g}^{-1}$ ) and heavily infected (>50000 eggs $\mathrm{g}^{-1}$ ), according to cut-off points set by $\mathrm{WHO}^{27}$. Of those with hookworm, 98\% were lightly (1-1999 eggs g $^{-1}$ ) and $2 \%$ moderately infected (2000-3999 eggs g $\left.{ }^{-1}\right)^{22}$.

\section{Biochemical data}

The mean retinol level was $26.7 \mu \mathrm{g} \mathrm{dl}^{-1} \pm 7.0$ (SD) (Table 1). 
Table 1 Anthropometric and biochemical measures and helminth infection levels in 164 Bangladeshi school children

\begin{tabular}{|c|c|c|c|}
\hline Variables & Mean \pm SD & Median & 25-75 percentile \\
\hline $\begin{array}{l}\text { Anthropometric } \\
\text { Height }(\mathrm{cm}) \\
\text { Weight }(\mathrm{kg}) \\
\text { W/H (z-score)* }\end{array}$ & $\begin{aligned} 131.9 & \pm 8.8 \\
25.5 & \pm 5.7 \\
-1.27 & \pm 0.76\end{aligned}$ & & \\
\hline $\begin{array}{l}\text { Biochemical† } \\
\text { Haemoglobin }\left(\mathrm{g} \mathrm{dl}^{-1}\right) \\
\text { Ferritin }\left(\mu \mathrm{gl}^{-1}\right) \\
\text { Retinol }\left(\mu \mathrm{g} \mathrm{dl}^{-1}\right) \\
\text { Beta-carotene }\left(\mu \mathrm{g} \mathrm{dl}^{-1}\right)\end{array}$ & $\begin{array}{l}12.1 \pm 1.0 \\
26.7 \pm 7.0\end{array}$ & $\begin{array}{r}20.5 \\
4.9\end{array}$ & $\begin{array}{l}11-32 \\
3.4-7.9\end{array}$ \\
\hline $\begin{array}{l}\text { Helminths } \\
\text { Ascaris }\left(\mathrm{eggs} \mathrm{g}^{-1}\right) \\
\text { Hookworm }\left(\mathrm{eggs} \mathrm{g}^{-1}\right)\end{array}$ & & $\begin{array}{r}1600 \\
0\end{array}$ & $\begin{array}{c}600-4450 \\
0-250\end{array}$ \\
\hline
\end{tabular}

Twenty per cent had serum retinol values $<20 \mu \mathrm{g} \mathrm{dl}^{-1}$, a cut-off point designated for low vitamin A status ${ }^{28}$ and $70 \%$ of the children had values $<30 \mu \mathrm{g} \mathrm{dl}^{-1}$. Those reporting $\mathrm{XN}$ had barely significantly lower serum retinol levels than those without, $24.4 \mu \mathrm{g} \mathrm{dl}^{-1}$ compared to $27.2 \mu \mathrm{g} \mathrm{dl}^{-1}$ $(P=0.05)$. The median value of $\beta$-carotene was $4.9 \mu \mathrm{g} \mathrm{dl}^{-1}$ (25-75 percentile: $3.4-7.9 \mu \mathrm{g} \mathrm{dl}^{-1}$ ). There was a statistically significant positive linear correlation between serum retinol and $\beta$-carotene $(r=0.44, P<0.001)$.

Thirty-one per cent were below the cut-off point for anaemia for children in this age group, $11.5 \mathrm{~g} \mathrm{dl}^{-1}$ for $\mathrm{Hb}^{1}$. Thirty per cent had iron deficiency as classified by serum ferritin levels lower than $12.0 \mu \mathrm{g} \mathrm{l}^{-1}$ and $14 \%$ were suffering from iron deficiency anaemia $\left(\mathrm{Hb}<11.5 \mathrm{~g} \mathrm{dl}^{-1}\right.$ and serum ferritin $\left.<12.0 \mu \mathrm{gl}^{-1}\right)^{1}$.

\section{Interactions}

Table 3 shows the relationship between serum retinol concentration and other indicators. Children with serum retinol concentrations $>30 \mu \mathrm{g} \mathrm{dl}^{-1}$ had significantly higher mean $\mathrm{Hb}$ and median serum ferritin concentrations than children with serum retinol concentrations $<20 \mu \mathrm{g} \mathrm{dl}^{-1}(P=$ 0.005 in both cases). Children reporting fever the week

Table 2 Proportions (\%) of children in different dietary intake categories

\begin{tabular}{lrcc}
\hline & \multicolumn{3}{c}{$\begin{array}{c}\text { Times eaten } \\
\text { during the past week }\end{array}$} \\
\cline { 2 - 4 } & 0 & 1 & 2 or more \\
\hline Plant sources of $\beta$-carotene & 16 & 17 & 67 \\
DGLV & 23 & 18 & 59 \\
YOFV & 68 & 18 & 14 \\
Animal sources of vitamin A & 8 & 10 & 82 \\
$\quad$ Liver & 78 & 22 & 0 \\
Eggs & 50 & 27 & 23 \\
Milk & 24 & 23 & 53 \\
Small fish & 53 & 18 & 29 \\
Meat & 35 & 19 & 46
\end{tabular}

DGLV, dark green leafy vegetables; YOFV, yellow/orange fruits and vegetables. preceding the interview had significantly higher serum ferritin values than those without: $28.5 \mu \mathrm{gl}^{-1}$ compared to $22.5 \mu \mathrm{gl}^{-1}(P=0.03)$. No significant differences were seen between boys and girls in any of the biochemical parameters.

No association was found between the severity of infection with Ascaris and the levels of serum retinol, $\mathrm{Hb}$ or ferritin. However, those who were positive for hookworm had significantly lower $\mathrm{Hb}\left(11.7 \mu \mathrm{gl}^{-1} \mathrm{com}-\right.$ pared to $\left.12.1 \mathrm{~g} \mathrm{dl}^{-1}, P=0.03\right)$ and ferritin values $\left(15.0 \mu \mathrm{g} \mathrm{l}^{-1}\right.$ compared to $\left.24.0 \mu \mathrm{gl}^{-1}, P=0.003\right)$. Similarly, the proportion of children with iron deficiency ( $43 \%$ compared to $24 \%, P=0.02$ ) and anaemia (43\% compared to $27 \%, P=$ 0.04 ) was greater among those positive for hookworm, as well as the number with iron deficiency anaemia $(24 \%$ compared to $10 \%, P=0.03$ ) (Table 4). Among those with lower vitamin A status, hookworm infection had a significant impact on ferritin levels, whereas this effect was not significant among those with better vitamin A status (Table 5). Among those positive for hookworm, higher vitamin $A$ status was significantly associated with higher ferritin status, but this effect was not significant among those without hookworm infection.

We confirmed through multiple regression analysis that vitamin A and hookworm had strong and independent associations with normalized (log-transformed) serum ferritin status. However, the interaction term (hookworm $x$ serum retinol) was not significant $(P=0.6)$. Thus we cannot say that our hypothesis was supported: we have no evidence that hookworm had a greater effect on iron status among children with lower vitamin A status.

\section{Discussion}

In this study, we only included children in grades 3-5 from two governmental schools, and purposely included all those with intestinal parasites in the sample. Thus, these children are likely to be worse off than the average school child in the parameters measured. On the other hand, 
Table 3 Biochemical and anthropometric measurements and helminth infection levels in relation to serum retinol levels

\begin{tabular}{llllc}
\hline & \multicolumn{3}{c}{ Serum retinol $\left(\mu \mathrm{g} \mathrm{dl}^{-1}\right)$} & \\
\cline { 2 - 4 } Indicators* & \multicolumn{1}{c}{$20(n=33)$} & $20-30(n=79)$ & $>30(n=49)$ & $P$ value† \\
\hline $\mathrm{Hb}\left(\mathrm{g} \mathrm{dl}^{-1}\right)$ & $11.7 \pm 1.0$ & $12.0 \pm 0.9$ & $12.4 \pm 1.0$ & 0.005 \\
Ferritin $\left(\mu \mathrm{gl}^{-1}\right) \ddagger$ & $14.0(7.0-25.0)$ & $19.0(11.0-34.0)$ & $26.0(16.0-34.5)$ & $0.005 \S$ \\
Weight $(\mathrm{g})$ & $24.4 \pm 4.2$ & $25.1 \pm 5.1$ & $27.2 \pm 7.0$ & 0.052 \\
Height $(\mathrm{cm})$ & $129.3 \pm 9.0$ & $131.7 \pm 8.6$ & $134.2 \pm 9.0$ & 0.048 \\
W/H & -1.38 & -1.33 & -1.01 & 0.10 \\
Ascaris $\left(\mathrm{eggs} \mathrm{g}^{-1}\right) \ddagger$ & $1400(0-6400)$ & $1800(0-4800)$ & $1800(800-3600)$ & $0.19 \S$ \\
Hookworm $\left(\mathrm{eggs} \mathrm{g}^{-1}\right) \ddagger$ & $0(0-100)$ & $0(0-400)$ & $0(0-0)$ & $0.29 \S$ \\
Meat intake (times eaten/week) & $1.28 \pm 1.5$ & $2.43 \pm 2.3$ & $2.15 \pm 2.0$ & 0.12 \\
\hline
\end{tabular}

*Mean \pm SD.

†ANOVA comparing the three group differences.

¥Median (25-75 percentile).

§Kruskal-Wallis test.

school-going children may have a higher nutritional status than those not attending school. In this part of Bangladesh (rural Rajshahi Division), $78 \%$ of the boys and $76 \%$ of the girls aged 6-10 years enrol in school but only approximately $40 \%$ eventually reach grade $5^{29}$. Furthermore, the lack of absence of differences in nutritional status between boys and girls may be due to selection bias, with boys from slightly better-off families being sent to private schools.

\section{Vitamin A status}

The study showed that $20 \%$ of the children had levels below $20 \mu \mathrm{g} \mathrm{dl}^{-1}$ for serum retinol, a cut-off value defined as low vitamin A status and an additional 50\% were below $30 \mu \mathrm{g} \mathrm{dl}^{-1}$. A study of 242 school children in urban Dhaka $^{10}$, aged $5-12$ years, found that about $20 \%$ of the children had serum retinol levels of less than $30 \mu \mathrm{g} \mathrm{dl}^{-1}$ and $4 \%$ had levels of less than $20 \mu \mathrm{g} \mathrm{dl}^{-1}$, suggesting that our study population was more nutritionally deprived. On the other hand, the mean serum retinol value of $26.7 \mu \mathrm{g} \mathrm{dl}^{-1}$ found in our study was similar to that seen in a study of children aged 9-15 years in Rangpur District, where the mean serum retinol levels of children with $(n=22)$ and without $(n=21)$ night blindness were $25.2 \mu \mathrm{g} \mathrm{dl}^{-1}$ and $29.2 \mu \mathrm{g} \mathrm{dl}^{-1}$, respectively ${ }^{11}$. Nineteen per cent of the children in our study reported being night blind. We did not confirm this, but similar to the case in Rangpur, XN children had significantly lower serum retinol values.

Very few studies have looked at the $\beta$-carotene status of primary school children. However, our median $\beta$-carotene concentration, $4.9 \mu \mathrm{g} \mathrm{dl}^{-1}$, was similar to the $4.0 \mu \mathrm{g} \mathrm{dl}^{-1}$ found in Indonesian primary school children selected as being anaemic ${ }^{30}$. The correlation between serum retinol and $\beta$-carotene was very high $(r=0.44, P<0.001)$. Thus, children with a higher serum retinol concentration probably had a higher carotene intake and/or better absorption. The frequency of intake of vitamin A-rich food sources was found to be low. Twenty-four per cent, $50 \%$, $53 \%$ and $78 \%$ did not consume any milk, eggs, small fish or liver, respectively, the week preceding the interview and $35 \%$ did not consume any meat. Even though available on the market, $\beta$-carotene-rich foods were not widely eaten; $23 \%$ and $68 \%$ did not eat any dark green leafy vegetables or yellow/orange fruits or vegetables, respectively, in the last week. This is similar to the Rangpur study where 16.8\% of the children $<9$ years old did not eat any dark green leafy vegetables the last 3 days prior to the interview ${ }^{31}$.

\section{Iron status and anaemia}

In our study, 31\% were anaemic, 30\% suffered from iron deficiency and 14\% from iron deficiency anaemia, using the threshold values $11.5 \mathrm{~g} \mathrm{dl}^{-1}$ for $\mathrm{Hb}$ and $12 \mu \mathrm{gl}^{-1}$ for ferritin. Despite being selected as a group likely to be at high risk, this level of anaemia was lower than the $67-81 \%$ found in other studies of rural children in Bangladesh ${ }^{2,32,33}$. Findings do vary greatly, for example Salmatullah and Yusuf $^{34}$ found an anaemia level of $50 \%$ but Ahmed et al. ${ }^{35}$ only a level of $20 \%$ in Dhaka school children. Our low figure could have three possible explanations:

1. Selection bias in how our sample was chosen. This seems an unlikely explanation since we oversampled children with helminthiasis. On the other hand, meat

Table 4 Numbers of children with iron deficiency, anaemia and iron deficiency anaemia in relation to hookworm infection*

\begin{tabular}{lcccr}
\hline & Iron deficiency: $n(\%)$ & Anaemia: $n(\%)$ & Iron deficiency anaemia: $n(\%)$ & Total $(n)$ \\
\hline Hookworm & $18(43) \dagger$ & $19(43)$ & $10(24)$ & $44 \ddagger$ \\
Yes & $29(24)$ & $33(27)$ & $12(10)$ & $120 \S$ \\
No & 0.02 & 0.04 & 0.03 & \\
$P$ value $\dagger$ & & & & \\
\hline
\end{tabular}

*Iron deficiency $=$ ferritin $<12.0 \mu \mathrm{gl}^{-1}$; anaemia $=\mathrm{Hb}<11.5 \mathrm{~g} \mathrm{dl}^{-1}$; iron deficiency anaemia $=$ ferritin $<12.0 \mu \mathrm{gl}^{-1}$ and $\mathrm{Hb}<11.5 \mathrm{~g} \mathrm{dl}^{-1}$. †Chi-square test.

‡Positive for hookworm.

$\S$ Negative for hookworm. 
Table 5 Ferritin and haemoglobin status in relation to vitamin A status and hookworm infection

\begin{tabular}{|c|c|c|c|c|}
\hline & \multicolumn{2}{|c|}{ Vitamin $\mathrm{A} \leqslant 25 \mu \mathrm{g} \mathrm{dl}^{-1}(n=66)$} & \multicolumn{2}{|c|}{ Vitamin $\mathrm{A}>25 \mu \mathrm{g} \mathrm{dl}^{-1}(n=95)$} \\
\hline & Ferritin* & $\mathrm{Hb} \dagger$ & Ferritin* & $\mathrm{Hb} \dagger$ \\
\hline $\begin{array}{l}\text { Hookworm status } \\
\text { Positive }\end{array}$ & $\begin{array}{c}9.0^{\mathrm{a}}(6.1-18.2) \\
(n=18)\end{array}$ & $\begin{array}{c}11.5 \pm 1.0 \\
\quad(n=18)\end{array}$ & $\begin{array}{c}16.5^{\mathrm{b}}(12.5-31.2) \\
(n=24)\end{array}$ & $\begin{array}{c}12.0 \pm 1.2 \\
(n=24)\end{array}$ \\
\hline Negative & $\begin{array}{c}20.5^{\mathrm{b}}(9.2-37.5) \\
(n=48)\end{array}$ & $\begin{array}{c}11.9 \pm 0.94 \\
(n=48)\end{array}$ & 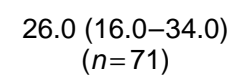 & $\begin{array}{c}12.3 \pm 0.84 \\
(n=71)\end{array}$ \\
\hline
\end{tabular}

*Median (25-75 percentile).

†Mean \pm SD.

${ }^{a b}$ Significantly different from each other (Mann-Whitney U-test, $P=0.01$ ).

consumption appeared to be relatively high in this group - $65 \%$ ate meat at least once the week preceding the interview (see Table 2).

2. The geographic variability in prevalence. This is worth investigating, as it may yield additional clues as to causation.

3. A secular trend toward improved iron status. This is likely to be occurring, at least to some extent, as vitamin A status in the country improves ${ }^{8}$. However, we know little about trends in either VAD or anaemia among children of school age.

Half of the anaemia could not be attributable to iron deficiency, but presumably was due to other causes not investigated in this study, for example malaria and/or thalassaemias ${ }^{36}$. Thus, there may be a need for caution in the widespread assumption that most of the anaemia seen in developing countries is attributable to iron deficiency. However, serum ferritin has been shown to increase during infection, thus giving false negative results ${ }^{37,38}$. Even though we excluded those with elevated CRP levels $\left(>10 \mu \mathrm{gl}^{-1}\right)$, children reporting a fever in the past week had a significantly higher serum ferritin than those not reporting fever (28.5 compared to $22.5 \mu \mathrm{gl}^{-1}, P=0.03$ ), whereas $\mathrm{Hb}$ concentrations were the same $(P=0.9)$. Suggestions have been made to use a higher cut-off value for serum ferritin in populations where infections and/or inflammatory diseases are highly prevalent ${ }^{39,40}$. By, for example, using the cut-off value of 20 instead of $12 \mu \mathrm{g} \mathrm{l}$ l$^{-1}, 49 \%$ would be classified as iron deficient, instead of $30 \%$. However, over one-third of the cases of anaemia would still not be iron deficient.

\section{Interactions}

We found an association between serum vitamin A levels and iron status, as have others ${ }^{3,4,10,41}$. Children with low vitamin A status had significantly reduced ferritin and $\mathrm{Hb}$ levels. Thus, we agree with the suggestions that have been made that programmes designed to reduce anaemia should include efforts to improve vitamin A status ${ }^{42}$.

The proportion of iron deficiency anaemia among those positive for hookworm was significantly higher, $24 \%$ compared to $10 \%(P=0.03)$, among the non-infected, despite the fact that most hookworm infection was light $\left(<2000\right.$ eggs g $^{-1}$ faeces $)$. In spite of the lower level of anaemia than has been found in other studies, the iron stores of the study population may be small so that even a light hookworm infection may be sufficient to cause iron deficiency anaemia.

We were unable to find statistical support for our hypothesis. It would appear that hookworm exerts its impact on iron status independently of the vitamin A status of the host.

We conclude that the iron deficiency found among the primary school children studied here is related in part to both VAD and hookworm. Since VAD, iron deficiency and iron deficiency anaemia were common in the group studied, we suggest giving more attention to this group in planning micronutrient interventions. Examples of special programmes which could be targeted towards primary school children are nutrition and hygiene education, school demonstration gardens, school feeding with micronutrient-rich foods and school-based deworming programmes. Albendazole might be a preferable anthelminthic drug as it has a better cure rate $(57-100 \%)$ for hookworm than mebendazole $(22-30 \%)^{43}$.

\section{Acknowledgements}

This study would not have been possible without the invaluable support and assistance of the director of the Worldview International Foundation, Mr Sirajul Islam, and his field staff in Thakurgaon. We are also extremely grateful to Mrs Zareen, Mr Shamsu, Mr Zakir and Dr Aktaruzzaman, all from Dhaka University, for translation, field assistance and laboratory analyses at the Institute of Nutrition and Food Science at Dhaka University. We are also deeply thankful to the headmasters and teachers at Chandan Bari School and Balirangi School for their invaluable support and assistance. Thanks also to the Department of Clinical Chemistry, Uppsala University. The study was supported by grants from Sarec (Swedish Agency for Research Cooperation in the Developing Countries) (SWE-1996-155) and InDevelop, Uppsala University.

\section{References}

1 WHO. Preventing and Controlling Iron Deficiency Anaemia through Primary Health Care. A Guide for Health Administrators and Programme Managers. Geneva: World Health Organization, 1989. 
2 Ahmed K, Hassan N. Nutrition Survey of Bangladesh 198182. Dhaka: Institute of Nutrition and Food Science, 1983.

3 Ahmed F, Khan M, Karim R, et al. Serum retinol and biochemical measures of iron status in adolescent schoolgirls in urban Bangladesh. Eur. J. Clin. Nutr. 1996; 50: 346-51.

4 Bloem MV, Wedel M, Egger RJ, et al. Iron metabolism and vitamin deficiency in children in northeast Thailand. Am.J. Clin. Nutr. 1989; 50: 332-8.

5 Wolde-Gebriel Z, West C, Haile Gebru Tadesse A, et al. Interrelationship between vitamin $\mathrm{A}$, iodine and iron status in school children in Shoa Region, Central Ethiopia. $\mathrm{Br} . J$. Nutr. 1993; 70: 593-607.

6 Meija LA, Chew F. Haematological effect of supplementation anemic children with vitamin A alone and in combination with iron. Am. J. Clin. Nutr. 1988; 48: 595-600.

7 Cohen N, Rahman H, Sprague J, Jalil M, Leemhuis de Regt E, Mitra M. Prevalence and determinants of nutritional blindness in Bangladesh children. World Health Stat. Q. 1985; 38:317-30.

8 ACC/SCN. 25th Session: Working Group on Vitamin A Deficiency, 1998. The Year of Vitamin A. Oslo, Norway: United Nations Administrative Committee on Coordination/ Sub-Committee on Nutrition, 1998.

9 WHO/UNICEF. Global Prevalence of Vitamin A Deficiency. WHO Micronutrient Deficiency Information System (MDIS), Working Paper No. 2. WHO/UNICEF Doc. WHO/NUT/95.3. Geneva: World Health Organization, 1995.

10 Ahmed F, Barua S, Mohiduzzaman M, et al. Interaction between growth and nutrient status in shool-age children of urban Bangladesh. Am. J. Clin. Nutr. 1993; 58: 334-8.

11 Hussain A, Kvåle G. Serum vitamin A in relation to socioeconomic, demographic and dietary characteristics in Bangladeshi children. Acta Paediatr. 1996; 85: 971-6.

12 Martin J, Keymer A, Isherwood R, Wainwright S. The prevalence and intensity of Ascaris lumbricoides infections in moslem children from northern Bangladesh. Trans. $R$. Soc. Trop. Med. Hyg. 1983; 77: 702-6.

13 Hall A, Anwar KS, Tomkins AM. Intensity of reinfection with Ascaris lumbricoides and its implications for parasite control. Lancet 1992; 330: 1253-7.

14 Sivakumar B, Reddy V. Absorption of vitamin A in children with ascariasis. J. Trop. Med. Hyg. 1975; 78: 114-15.

15 Jalal F, Nesheim M, Agus Z, Sanjur D, Habicht J. Serum retinol concentrations in children are affected by food sources of beta-carotene, fat intake, and anthelmintic drug treatment. Am. J. Clin. Nutr. 1998; 68: 623-9.

16 Pritchard DI, Quinnell RJ, Moustafa M, et al. Hookworm (Necator americanus) infection and storage iron depletion. Trans. R. Soc. Trop. Med. Hyg. 1991; 85: 235-8.

17 Stoltzfus RJ, Chwaya HM, Tielsch JM, Schulze KJ, Albonico M, Savioli L. Epidemiology of iron deficiency anemia in Zanzibari schoolchildren: the importance of hookworms. Am. J. Clin. Nutr. 1997; 65(1): 153-9.

18 Roche M, Larysse M. The nature and causes of 'hookworm anemia'. Am.J. Trop. Med. 1966; 15: 1031-100.

19 Farid Z, Nichols J, Bassily S, Schulert A. Blood loss in pure Ancylostoma duodenale infection in Egyptian farmers. Am. J. Trop. Med. Hyg. 1965; 14: 375-8.

20 Larysse M, Roche M. The relationship between anemia and hookworm infection: results of surveys of rural Venezuelan population. Am. J. Hyg. 1964; 79: 279-301.

21 Dreyfuss ML, Shrestha JB, Khatry EK, Stoltzfus RJ, Albonico M, Savioli L. Relationship between iron status and helminth infection among pregnant women in Nepal (Abstract). FASEB J. 1996; 10: A730.

22 Stoltzfus RJ, Dreyfuss ML, Hababuu MC, Albonico M. Hookworm control as a strategy to prevent iron deficiency. Nutr. Rev. 1997; 55: 223-32.

23 Beaton G, Kelly A, Kevany J, Martorell R, Mason J. Appropriate Use of Anthropometric Indices in Children. ACC/SCN State of the Art Series Nutrition Policy Discussion
Paper No. 7. Geneva: United Nations Administrative Committee on Coordination/Sub-Committee on Nutrition, 1990.

24 Suzuki N. Color Atlas of Human Helminth Eggs. Tokyo: JAPC and JOICEP, 1981.

25 WHO. Measuring Change in Nutritional Status. Geneva: World Health Organization, 1988.

26 FAO. Requirements of Vitamin A, Iron, Folate, and Vitamin $B$-12. FAO Food and Nutrition Series No. 23. Rome: Food and Agricultural Organization, 1988.

27 WHO. Prevention and Control of Intestinal Parasitic Infections. Geneva: World Health Organization, 1987.

28 WHO/UNICEF. Indicators for Assessing Vitamin A Deficiency and their Application in Monitoring and Evaluating Intervention Programs. Geneva: World Health Organization, United Nations Children's Fund, 1994.

29 UNICEF BBoSa. Progotir Pathey. Progress Toward the Achievment of the Goals for the 1990s. Bangladesh Bureau of Statistics, Ministry of Planning, Government of the People's Republic of Bangladesh and UNICEF, 1995.

30 De Pee S, West CE, Permaesih D, Martuti S, Muhilal, Hautvast JG. Orange fruit is more effective than are dark-green, leafy vegetables in increasing serum concentrations of retinol and beta-carotene in schoolchildren in Indonesia. Am. J. Clin. Nutr. 1998; 68(5): 1058-67.

31 Hussain A, Kvåle G. Sustainability of a nutrition education programme to prevent night-blindness in Bangladesh. Trop. Med. Int. Health 1996; 1: 43-51.

32 Saha A, Ahmad K. Anemia in two rural Bangladesh communities, with and without the supply of safe drinking water. Bangladesh J. Nutr. 1991; 4: 1-8.

33 Saha A, Ahmad K. Iron and micronutrient supplementation after deworming: an effective measure to raise hemoglobin level of anemic children in rural Bangladesh. Bangladesh J. Nutr. 1989; 2: 1-7.

34 Salmatullah Q, Yusuf HKM. Report of the Iodine Deficiency Disorders Indicator Study in Savar, Bangladesh. Dhaka: University of Dhaka, 1997.

35 Ahmed F, Khan MR, Mohiduzzaman M, et al. Relationship between growth and nutrient status in school children of urban Bangladesh. In: Said HM, Rahman MA, Abdulla M, Vohora SB, Athar M, eds. Proceedings of the International Symposium on Trace Elements and Liver Diseases. Karachi, Pakistan: Hamdard Foundation, 1996; 26-33.

36 Gillespie S, Johnston J. Expert Consultation on Anemia Determinants and Interventions. Ottawa: Micronutrient Initiatives, 1998.

37 Lipschitz D, Cook J, Finch C. A clinical evaluation of serum ferritin as an index of iron stores. N. Engl.J. Med. 1974; 290: 1213-16.

38 Hulthén L, Lindstedt G, Hallberg L. Effect of a mild infection on serum ferritin concentration - clinical and epidemiological implications. Eur. J. Clin. Nutr. 1998; 52: 376-9.

39 Punnonen K, Irjala K, Rajamäki A. Serum transferrin receptor and its ratio to serum ferritin in the diagnosis of iron deficiency. Blood 1997; 89: 1052-7.

40 Mast A, Blinder MA, Gronowski AM, Chumley C, Scott MG. Clinical utility of the soluble transferrin receptor and comparison with serum ferritin in several populations. Clin. Chem. 1998; 44: 45-51.

41 Suharno D, Muhilal. Vitamin A and nutritional anaemia. Food Nutr. Bull. 1996; 17: 7-10.

42 Bloem M. Interdependence of vitamin A and iron: an important association for programmes of anemia control. Proc. Nutr. Soc. 1995; 54: 501-8.

43 WHO. Report of the WHO Informal Consultation on the Use of Chemotherapy for the Control of Morbidity due to Soiltransmitted Nematodes in Humans. WHO Schistosomiasis and Intestinal Parasites Unit Division of Control of Tropical Diseases Report No. WHO/CTD/SIP/96.2. Geneva: World Health Organization, 1996. 